\title{
Clinical manifestations of acute asthma in children at the Department of Child Health Cipto Mangunkusumo Hospital
}

\author{
Kadek Ayu Lestari, MD; Imam Budiman, MD; Sudigdo Sastroasmoro, MD, PhD
}

\begin{abstract}
Background Acute asthma is an asthma attack or worsening of asthma manifestation and pulmonary function. Severe asthma attack might be prevented by early recognition of the attack and appropriate therapy. Clinical manifestations of asthma in children vary widely, so does the assessment of the attack that is often not accurately defined by doctors. This leads to delayed and inadequate treatment of the attack.

Objective This study aimed to know the clinical manifestations of acute asthma in children at the Department of Child Health, Medical School University of Indonesia/Cipto Mangunkusumo Hospital.

Methods This was a descriptive, cross sectional study, conducted at the emergency room (ER), the Pediatric Pulmonology Outpatient Clinic, and the Pediatric Outpatient Clinic. Subjects were asthmatics who were having attack and aged 2-18 year-old. Data of age, sex, pulse rate, respiratory rate, duration of attack, expiratory, and inspiratory effort signs were obtained by history and physical examination followed by the assessment of attack severity.

Results Subjects consisted of 92 children, mostly obtained from the ER $(40 \%)$, with male to female ratio of $1.5: 1$ and average age of 5.8 years old. Most of the subjects had mild attack (83\%) and duration of attack of less than 24 hours (56\%). Most subjects (70\%) only had signs of increased expiratory effort, in which all of them had mild attack. The rest of the subjects showed the combination of inspiratory and expiratory efforts; 12 patients with mild attack, 15 with moderate attack, and 1 with severe attack.

Conclusion Patients who only showed expiratory effort usually had mild attack. Patients showing expiratory and inspiratory efforts usually had mild or moderate attack. Treatment should be tailored to the degree of attack [Paediatr Indones 2003;43:132135].
\end{abstract}

Keywords: clinical manifestation, acute asthma, inspiratory effort, expiratory efforts, children

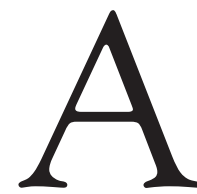

sthma is the most prevalent chronic disease in children and is still a major problem in community. ${ }^{1}$ Recently there is an increase of prevalence and degree of attack all around the world. ${ }^{2}$ The prevalence of asthma varies due to the difference in the definition of asthma and the methods of the studies. ${ }^{1,2}$ The morbidity of childhood asthma is also reported to be increasing, despite a significant progress in treating severe acute asthma and the introduction of prophylactic drugs for maintenance treatment. The morbidity of asthma is difficult to define, but the hospitalization rate and the school absence of children with acute asthma are increasing around the world. ${ }^{3}$ The mortality rate of acute asthma tends to increase in several countries. A retrospective study found that the mortality of asthma was related to underestimation of the severity of a fatal attack, delay in obtaining help, and inappropriate treatment. ${ }^{3}$

Acute asthma is an asthmatic attack or worsening of asthmatic signs and pulmonary function, usually implying failure of long-term treatment or an exposure to a trigger. ${ }^{2,4}$ Severe asthma attack might be

From the Department of Child Health, Medical School, University of Indonesia, Cipto Mangunkusumo Hospital, Jakarta.

Reprint requests to: Kadek Ayu Lestari, MD, Department of Child Health, Medical School, University of Indonesia, Cipto Mangunkusumo Hospital, Jakarta, Indonesia. Tel. 62-21-3907740, Fax. 62-21-3907743. 
prevented or at least attenuated by early recognition of the attack and intensive treatment. ${ }^{4}$ Clinical manifestations of childhood asthma vary widely and are more severe than those in adults. Dyspnea, wheezing, cough, tachypnea, prolonged expiration, cyanosis, chest hyperinflation, tachycardia, and paradoxical pulse are the usual characteristics. ${ }^{5}$ Other clinical manifestations apart from wheezing are usually left unnoticed by parents, leading to delay in diagnosis and inadequate treatment. Asthmatic patients who came to the emergency room (ER) get delayed and inadequate treatment by doctors due to inaccuracy in the assessment of the severity, leading to increased hospitalization rate. This study aimed to find out the clinical manifestations of acute asthma at the Department of Child Health, Medical School of University of Indonesia/Cipto Mangunkusumo Hospital, Jakarta.

\section{Methods}

This was a descriptive cross sectional study done in July 2002; 92 acute asthmatic patients who visited the ER, the Pediatric Pulmonology Outpatient Clinic, and the Pediatric Outpatient Clinic at Cipto Mangunkusumo Hospital were recruited to fulfill the required sample size.

Subjects were asthmatic patients who met the inclusion criteria as follow: was having acute asthmatic attack, aged 2-18 years old, had never been treated in any other hospital during the present attack, and parents signed the informed consent.

Age, sex, duration of attack, pulse rates, respiratory rates, prolonged expiration, wheezing, retraction of intercostals, epigastric, suprasternal space, use of sternocleidomastoid muscles, and nasal flaring were recorded by history taking and physical exams by the authors. Subjects coming to the ER were assessed by other pediatric residents besides the first author.

The definition of asthma attack was according to the National Consensus of Childhood Asthma (2002). ${ }^{6}$ The degree of the asthma attack was assessed using the clinical assessment tool issued by the $\mathrm{Na}$ tional Consensus of Childhood Asthma. ${ }^{4}$ Acute asthma is an episode of progressive worsening of signs of coughing, dyspnea, wheezing, chest tightness, and various combinations of the signs. ${ }^{4}$ Duration of attack is the lapse of time between the onset of attack to the time the subject received treatment in the ER/ outpatient clinic. Signs of expiratory effort consisted of prolonged expiration and wheezing, inspiratory effort consisted of the use of accessory respiratory muscles and the presence of retraction. Signs of expiratory effort and inspiratory effort are the combination of the two signs categories.

\section{Results}

There were 37 subjects obtained from the ER (40\%), 35 from the Pediatric Pulmonology Outpatient Clinic (38\%), and 20 from the Pediatric Outpatient Clinic (22\%). Males were more prevalent $(61 \%)$ with a male to female ratio of $1.5: 1$. The subjects were mostly between $2-5$ year-old (52\%) with an average age of 5.8 years old (Table 1 ).

Table 1. Distribution of acute asthma patients based ON AGE GROUP AND SEX

\begin{tabular}{|c|c|c|c|}
\hline \multirow[t]{3}{*}{ Age group (years) } & \multicolumn{2}{|c|}{ Sex } & \multirow[t]{3}{*}{ Total (\%) } \\
\hline & Male & Female & \\
\hline & $\mathrm{n}(\%)$ & n (\%) & \\
\hline $2-5$ & $26(28)$ & $22(24)$ & 48 (52) \\
\hline $6-10$ & $22(24)$ & $13(14)$ & 35 (38) \\
\hline$>10$ & $8(9)$ & $1(1)$ & $9(10)$ \\
\hline Total & $56(61)$ & $36(39)$ & $92(100)$ \\
\hline
\end{tabular}

Of those 92 patients, 76 patients (83\%) had mild asthma attack whereas 15 patients and only 1 patient had moderate and severe attack respectively. The duration of attacks was mostly less than 24 hours (56\%) with mild attack (Table 2).

Table 2. Distribution of degree of asthmatic attack BASED ON DURATION OF ATTACK

\begin{tabular}{|c|c|c|c|c|}
\hline \multirow{3}{*}{$\begin{array}{l}\text { Duration } \\
\text { of attack } \\
\text { (hours) } \\
\end{array}$} & \multicolumn{3}{|c|}{ Degree of asthmatic attack } & \multirow{3}{*}{$\begin{array}{l}\text { Total } \\
\text { n (\%) }\end{array}$} \\
\hline & Mild & Moderate & Severe & \\
\hline & $\mathrm{n}(\%)$ & n (\%) & n (\%) & \\
\hline$<24$ & $45(49)$ & $7(8)$ & 0 & $52(56)$ \\
\hline $24-48$ & $15(16)$ & $4(4)$ & $1(1)$ & $20(22)$ \\
\hline$>48-72$ & $5(5)$ & $4(4)$ & 0 & 9 (10) \\
\hline$>72$ & $11(12)$ & 0 & 0 & $11(12)$ \\
\hline Total & $76(83)$ & $15(16)$ & $1(1)$ & $92(100)$ \\
\hline
\end{tabular}

Most subjects (70\%) had the signs of expiratory effort only and all of these subjects had a mild attack. No one had the signs of inspiratory effort only (Table 3). 
Table 3. Distribution of Degree of ASthMATIC ATtACK BASED ON CLINICAL MANIFESTATIONS

\begin{tabular}{lllll}
\hline Clinical manifestations & \multicolumn{2}{l}{ Degree of asthmatic attack } & Total \\
\cline { 2 - 4 } & Mild (\%) & Moderate (\%) & Severe (\%) & \\
\hline Expiratory effort & $64(70)$ & 0 & 0 & $64(70)$ \\
$\begin{array}{l}\text { Inspiratory effort } \\
\begin{array}{l}\text { Expiratory and } \\
\text { inspiratory efforts }\end{array}\end{array}$ & 0 & 0 & 0 & 0 \\
\hline Total & $12(13)$ & $15(16)$ & $1(1)$ & $28(30)$ \\
\hline
\end{tabular}

\section{Discussion}

The limitation of this study was that the data were obtained not only by the author but also by some other pediatric residents. They had been given some training on how to fill the study form so it was expected that errors in data collection might be prevented or minimized. In defining the duration of attack many parents could not precisely recall the time of onset so that the duration of attack was grouped in several time groups.

We found that male to female ratio was 1.5:1 with an average age of 5.8 year-old and most subjects were between $2-5$ years old (52\%). This result was similar to the result of Canny who reported a male to female ratio of 1.9:1 with an average age of 5.6 yearold, mostly between 1.4 years old (47\%). ${ }^{3}$ A similar retrospective study in Jakarta found the ratio was 1.6:1 with the most frequent age was $5-12$ years old. ${ }^{7}$ These results were in accordance with literatures that the incidence of asthma is different between boys and girls. The relation of asthma with sex was related to the anatomy of the airway. Males in their childhood had smaller airway caliber and higher airway muscles tone so that the clinical manifestation of asthma in boys tends to be more severe and more frequent. 8,9

We also found that most subjects (83\%) had mild attack. This result was similar to the previous asthma study in this department, $96.7 \%$ acute asthmatic patients who visited the ER had mild attack. ${ }^{7}$ But in that study they used the response to $\beta 2$-agonist inhalation to assess the severity of asthma attack. One study found that most asthma patients (80\%) who visited the ER and were hospitalized had a moderate or severe attack. ${ }^{10}$ Our study used the clinical assessment issued by the National Consensus of Childhood Asthma to assess the severity of attack. This tool tends to be subjective. Pulmonary function testing using spirometry is a better and objective tool for assessing of the severity of asthma attack. Unfortunately this test is not always available and is difficult to perform in children with severe asthma attack. ${ }^{4}$

Most of our subjects (56\%) had duration of attack of less than 24 hours and $49 \%$ of them had mild attack. This result was different to the study of De Marco et al, they found that the average time of asthma manifestations before arriving at the ER was 41 hours and mostly between 24 to 72 hours (59\%). ${ }^{3}$ Asthma manifestations of more than 24 hours would decrease the success of treatment and discharge from the ER. ${ }^{11}$ This finding was in accordance with some literatures, the shorter the duration from the onset of an attack to the treatment received, the higher the chance of the success of treatment.

Most of our subjects had signs of expiratory effort with mild attack. Subjects showing only the signs of increased inspiratory effort were not found in our study. This supports the evidence that in acute asthma there is a wide airway obstruction, which is a combination of bronchial muscles spasm, mucosal edema due to airway inflammation, and mucous plug. Airway obstruction leads to increased airflow resistance through the trachea and bronchus and decreases the flow rates due to narrowing and early closure of small airways. Those conditions decrease the pulmonary ability to expire the air. In the early stage of acute asthma it is usually very difficult for the patients to do expiration (expiratory effort) but inspiration might be done very well. ${ }^{12,13}$

Airway obstruction also traps some air and leads to excess pulmonary distention (hyperinflation). Pulmonary hyperinflation leads to a decrease of pulmonary compliance and a significant load to inspiratory muscles and inspiratory effort. ${ }^{14}$ In this study, when only increased expiratory effort was found then the degree of attack was usually mild. If signs of inspira- 
Kadek Ayu Lestari et al: Clinical manifestations of acute asthma in children

tory effort were also found, the proportion of the severity of attack was mostly mild to moderate. This was due to the assessment of severity of asthma attack using the National Consensus of Childhood Asthma that includes minimal retraction in mild attack, which showed inspiratory effort sign. The data above showed that the severity of asthma attack could be determined by the presence of expiratory effort or expiratory and inspiratory effort sign so that treatment can be done promptly. Treatment should be tailored to the degree of attack (mild, moderate, and severe). Our study did not find signs of only increased inspiratory effort due to the pathophysiology of acute asthma explained above.

We concluded that patients who only show expiratory effort usually have mild attack. Patients showing expiratory and inspiratory efforts usually have mild to moderate attack. Treatment should be tailored to the degree of attack.

\section{References}

1. Evans R, Gergen PJ. Epidemiology of allergy and asthma. In: Bierman CW, Pearlman DS, Shapiro GG, Busse WW, editors. Allergy, asthma, and immunology from infancy to adulthood. $3^{\text {rd }}$ ed. Philadelphia: WB Saunders; 1996. p. 79-88.

2. National Heart, Lung, and Blood Institute. World Health Organization. Global Initiative for Asthma: Global strategy for asthma management and prevention NHLBI/WHO workshop report 1995.

3. Canny GJ, Reissman J, Healy R, Schwartz C, Petrou C, Rebuck AS, et al. Acute asthma: observations regard- ing the management of a pediatric emergency room. Pediatrics 1989;83:507-12.

4. Unit Kerja Koordinasi Pulmonologi IDAI. Penanganan serangan asma pada anak. 1998 Desember 12-13; Bandung, Indonesia.

5. Sly M. Asthma. In: Behrman RE, Kliegman RM, Arvin AM, editors. Nelson textbook of pediatric. $15^{\text {th }}$ ed. Philadeplhia: WB Saunders; 1996. p. 628-40.

6. Unit Kerja Koordinasi Pulmonologi IDAI Tatalaksana Jangka Panjang (Bagian dari Konsensus Nasional Asma Anak. 2002 July; Denpasar, Indonesia.

7. Rahajoe N, Prastowo SP, Said M, Darmawan BS. Gambaran pasien serangan asma yang datang ke IGD RSCM tahun 1998. Abstract. Proceeding of the $11^{\text {th }}$ National Child Health Congress. 1999 July; Jakarta, Indonesia.

8. De Marco R, Locatelli F, Sunyer J, Burney P. Differences in incidence of reported asthma related to age in men and women. Am J Resp Crit Med 2000;162:68-74.

9. Weiss CT, Gold DR. Gender difference in asthma. Pediatr Pulmonol 1995;19:153-5.

10. Ordonez GA, Phelan PD, Olinsky A, Robertson CF. Preventable factors in hospital admissions for asthma. Arch Dis Child 1998;78:143-7.

11. Lula S, Newcomb RW. Emergency management of asthma in children. J Pediatr 1980;97: 346-50.

12. Guyton AL. Textbook of medical physiology. $7^{\text {th }}$ ed. Philadelphia: WB Saunders; 1984. p. 215-6.

13. Bierman W, Pearlman DS. Asthma. In: Chernick V, Kendig EL, editors. Kendig's Disorder of the Respiratory Tract in Children. $5^{\text {th }}$ ed. Philadelphia: WB Saunders; 1990. p. 557-76.

14. Martin JG, Shore SA, Angel LA. Mechanical load and inspiratory muscle action during induced asthma. Am Rev Respir Dis 1983;128:455-60. 